\title{
Functional assessment of women practising combat sports and team sports using the Functional Movement Screen
}

\author{
Dariusz Boguszewski ${ }^{1}$, Jakub Grzegorz Adamczyk ${ }^{1,2}$, Katarzyna Boguszewska ${ }^{3}$, \\ Dominika Wrzosek ${ }^{4}$, Natalia Mrozek ${ }^{4}$, Marta Waloch ${ }^{4}$, Dariusz Białoszewski ${ }^{1}$
}

1 Department of Rehabilitation, Physiotherapy Division, Medical University of Warsaw, Poland; ${ }^{2}$ Institute of Theory of Sport, University of Physical Education in Warsaw, Poland; 3 Piotr Skarga Catholic Educational Center in Warsaw, Poland; ${ }^{4}$ Students Science Society of Physiotherapy, Medical University of Warsaw, Poland

\section{Summary}

Study aim: The objective of the study was to reveal the functional limits of the motor system in women practising combat sports and team sports.

Material and methods: 102 women (mean age 25.2 years, body mass $62.2 \mathrm{~kg}$, body height $168.3 \mathrm{~cm}$ ) practising competitive ITF (International Taekwon-Do Federation) taekwon-do $(n=22)$, Brazilian jiu-jitsu (BJJ) $(n=15)$, football $(n=35)$ and basketball $(\mathrm{n}=30)$ participated in the study. The assessment tool was the FMS test, comprising 7 movement patterns scored on a scale of $0-3$.

Results: The studied female athletes earned medium scores. Women practising combat sports scored generally higher in the FMS test, although the difference was not significant (combat sports - mean value $15.57 \pm 2.39$, team sports - mean value $14.72 \pm 1.93$, difference $-p=0.07)$. Statistically significant differences $(p<0.05)$ were observed in the second (hurdle step) and the fifth pattern (active straight leg raise - ASLR). The aggregated FMS results of female taekwon-do (15.77) and BJJ athletes (15.22) were similar. Significant differences $(p<0.05)$ were observed in one pattern (ASLR). Women practising football (14.77) and basketball (14.67) attained a similar level of results in the test. Statistically significant differences were noted in two trials: footballers scored higher in the ASLR task $(p<0.05)$, and basketball players scored higher in rotary stability $(p<0.01)$.

Conclusion: A statistically significant result in the FMS test was obtained by martial arts athletes, which may point to a higher level of functional movement, which may be a result of more universal training.

Key words: Taekwondo - BJJ - Football - Basketball - Injury prevention - Functional limitations - Fundamental movement patterns

\section{Introduction}

The number of women practising competitive sport is increasing. Women train in disciplines formerly considered typically male, such as combat sports or other contact sports. Training and sport competition may create the risk of overload and injuries in the locomotor system; therefore, preventing injuries in sports is increasingly important $[8,11,24,28,33,35,36,37]$. Injury prevention is based on the correctly performed training, which has to be adjusted to the given sports discipline, as well as the needs and abilities of the athlete. Recovery between regular efforts of the athlete is also important $[9,10,14]$. The use of protective equipment lowers the risk of injury related to the direct sport combat (fight, match) [29, 40].
Core stability exercises and proprioceptive training $[5,6]$ play an important role in bodily injury prevention. Numerous studies confirm the rationale of neuromuscular training to diminish the frequency of bodily injuries. The exercises improve the stability and sense of joint position, while also developing impulsive muscular work $[6,21,32]$. Proprioceptive training developed by Hupperets et al. [21] reduced the risk of repeated ankle joint injury in athletes compared to the control group. On the other hand, studies of the use of neuromuscular strategies during warm-up have proven that such strategies may diminish the risk of lower limb injuries. Such strategies comprise stretching, strengthening, balance and agility exercises, as well as landing techniques [20]. A multi-faceted training programme comprising warm-up, muscular activation exercises, balance exercises, enhancing muscular 
strength and core muscle stability lowers the frequency of knee injuries in non-contact situations [25, 34, 38].

For the intervention to be efficient, it is necessary to adequately assess the features that may foster bodily injuries. Movement quality can be assessed using a string of tools, such as balance tests, the Rotational Test, the Core Muscle Strength and Stability Test or the Functional Movement Screen (FMS) [13, 15, 17, 18, 22, 23, 26, $31,33]$. There are a few studies where athletes of different disciplines are compared. The present study aimed to reveal the functional limits in women practising combat and team sports using the FMS test. Specific objectives were related to relationships between FMS results and number of injuries.

\section{Material and methods}

102 female taekwon-do ITF $(n=22)$ and Brazilian jiujitsu $(n=15)$ athletes, footballers $(n=35)$ and basketball players $(n=30)$ took part in the study (Table 1$)$. The mean age of participants was of $25.2 \pm 5.4$, and the mean training experience, $6.2 \pm 3.9$ years. The threshold for eligibility for the control group was taking part in training sessions at least three times a week, competing and at least two years of experience in the practised sport. Prior to the studies, an interview on medical history and prior musculoskeletal system injuries which might have hampered the results of the test was conducted, and persons with such disorders were excluded. Participation in the study was voluntary and anonymous.

The Functional Movement Screen test (designed by Gray Cook and Lee Burton) was the main research tool. The test was designed for the purpose of an objective analysis of human movement patterns in relation to their functional capacity, and for the purpose of predicting and preventing injuries among sportsmen. The three-dimensional evaluation of movement brings to light abnormalities in kinematic chains, as well as allowing for a comprehensive assessment revealing the asymmetry and significant functional limitations resulting from incorrect mobility and stability of the musculoskeletal system [17, 18]. The Functional Movement Screen consists of seven exercises testing the basic movement patterns: 1. Deep squat, 2. Hurdle step, 3. In-line lunge, 4. Shoulder mobility, 5. ASLR - active straight leg raise, 6 . Trunk stability push-up, 7 . Trunk rotation stability $[17,18]$.

The FMS is conducted before exercises, prior to the warm-up. The assessment is made in two planes: sagittal and coronal. The studied person does three repetitions of a specific test, and the person conducting the research assesses the best result. In case of doubts as regards the correctness of the pattern, the score is lower. Each side is assessed separately. Performance of each of the seven exercises mentioned above is graded on a 4-grade scale, in line with the established criteria. Each movement pattern in graded from 0 to 3 points ( 3 points are awarded to a person who executed a movement pattern in the correct manner, 2 points are awarded to a person who executed a movement pattern with compensation, 1 point is awarded to a person who did not manage to execute a movement pattern, 0 points are given to persons who experience pain during executing a movement pattern or during a provocative test). A participant of the study can obtain 21 points in total $[17,18]$.

The study was reinforced by a custom-created survey containing biometric identifiers and details of injuries and training.

The differences between the groups were established using the Mann-Whitney U test. The differences between the right and the left side (in the case of two-sided FMS) were calculated using Wilcoxon's signed-rank test. The relationships between particular variables (e.g., the results of the FMS test, training experience) were determined by the means of Spearman's rho correlation analysis. The minimal statistical significance was set at $\mathrm{p} \leq 0.05$.

\section{Results}

The studied athletes obtained results that demonstrated a medium predisposition to bodily injuries. Women practising combat sports scored generally higher in the Functional Movement Test, although the difference was not statistically significant. Statistically significant differences were noted in Test 2 (hurdle step) and Test 5 (ASLR). Athletes in Group 1 earned the highest scores in Test 5

Table 1. Biometric characteristic of examined athletes

\begin{tabular}{llccccc}
\hline Groups & Disciplines & Number of people & Age [years] & Body mass [kg] & Body height [cm] & $\begin{array}{c}\text { Training experience } \\
\text { [years] }\end{array}$ \\
\hline Combat & Taekwon-do & 22 & $24.8 \pm 3.4$ & $63.4 \pm 11.1$ & $168.6 \pm 7.7$ & $4.5 \pm 2.5$ \\
sports & BJJ & 15 & $22.8 \pm 3.3$ & $62.8 \pm 7.3$ & $165.2 \pm 6.4$ & $4.3 \pm 2.1$ \\
\multirow{2}{*}{ Team } & Football & 35 & $28.7 \pm 6.9$ & $59.7 \pm 6.7$ & $166.1 \pm 5.5$ & $5.6 \pm 3.2$ \\
sports & Basketball & 30 & $22.5 \pm 2.9$ & $63.9 \pm 8.2$ & $172.6 \pm 6.5$ & $8.7 \pm 3.6$ \\
\hline
\end{tabular}


(ASLR), while Group 2 did so in Test 4 (Shoulder mobility). The weakest scores were obtained in Test 7 (Rotary stability) (Table 2).

The generalised FMS results for taekwon-do and BJJ female athletes were similar. Significant differences (in favour of taekwon-do) were observed in one test (ASLR) (Table 3). Women practising football and basketball attained a similar level of results in the test. In two repetitions, statistically significant differences were noted - football players scored higher in Test 5 (ASLR), and basketball players scored higher in Test 7 (Rotary stability) (Table 4).

No significant asymmetries were noted: tallied scores of bilateral exercises were similar in both groups. Significant differences (between the left and the right side) were noted in Test 7 (Rotary stability) for martial arts athletes and in Test 4 (Shoulder mobility) for women practising team sports (Table 5).

As far as particular sports disciplines are considered, significant asymmetries were noted in the case of taekwon-

Table 2. Results of FMS test

\begin{tabular}{lcccccccc}
\hline Groups & Deep squat & Hurdle step & In-line lunge & $\begin{array}{l}\text { Shoulder } \\
\text { mobility }\end{array}$ & $\begin{array}{l}\text { Active straight } \\
\text { leg raise }\end{array}$ & $\begin{array}{l}\text { Trunk stability } \\
\text { push-up }\end{array}$ & $\begin{array}{l}\text { Rotary } \\
\text { stability }\end{array}$ & Sum \\
\hline $\begin{array}{l}\text { Combat } \\
\text { sports }\end{array}$ & $2.05 \pm 0.71$ & $2.27^{*} \pm 0.65$ & $2.14 \pm 0.63$ & $2.49 \pm 0.61$ & $2.54^{*} \pm 0.61$ & $2.05 \pm 0.74$ & $2.03 \pm 0.60$ & $15.57 \pm 2.38$ \\
$\begin{array}{l}\text { Team } \\
\text { sports }\end{array}$ & $2.17 \pm 0.72$ & $2.03 \pm 0.49$ & $2.12 \pm 0.62$ & $2.49 \pm 0.69$ & $2.28 \pm 0.54$ & $1.82 \pm 0.74$ & $1.82 \pm 0.43$ & $14.72 \pm 1.92$ \\
\hline
\end{tabular}

Differences between groups: ${ }^{*}-\mathrm{p}<0.05$.

Table 3. Results of FMS test in each disciplines of combat sports

\begin{tabular}{lcccccccc}
\hline Disciplines & Deep squat & $\begin{array}{c}\text { Hurdle } \\
\text { step }\end{array}$ & $\begin{array}{c}\text { In-line } \\
\text { lunge }\end{array}$ & $\begin{array}{c}\text { Shoulder } \\
\text { mobility }\end{array}$ & $\begin{array}{c}\text { Active straight } \\
\text { leg raise }\end{array}$ & $\begin{array}{c}\text { Trunk stability } \\
\text { push-up }\end{array}$ & $\begin{array}{c}\text { Rotary } \\
\text { stability }\end{array}$ & Sum \\
\hline Taekwon-do & $2.09 \pm 0.68$ & $2.27 \pm 0.70$ & $2.14 \pm 0.77$ & $2.68 \pm 0.48$ & $2.82 * \pm 0.39$ & $1.86 \pm 0.71$ & $1.91 \pm 0.61$ & $15.77 \pm 2.71$ \\
BJJ & $2.00 \pm 0.75$ & $2.27 \pm 0.59$ & $2.13 \pm 0.35$ & $2.20 \pm 0.68$ & $2.13 \pm 0.64$ & $2.33 \pm 0.72$ & $2.20 \pm 0.56$ & $15.27 \pm 1.87$ \\
\hline
\end{tabular}

Differences between groups: ${ }^{*}-\mathrm{p}<0.05$.

Table 4. Results of FMS test in each disciplines of team sports

\begin{tabular}{lcccccccc}
\hline Disciplines & Deep squat & Hurdle step & $\begin{array}{c}\text { In-line } \\
\text { lunge }\end{array}$ & $\begin{array}{c}\text { Shoulder } \\
\text { mobility }\end{array}$ & $\begin{array}{c}\text { Active straight } \\
\text { leg raise }\end{array}$ & $\begin{array}{c}\text { Trunk stability } \\
\text { push-up }\end{array}$ & $\begin{array}{c}\text { Rotary } \\
\text { stability }\end{array}$ & Sum \\
\hline Football & $2.23 \pm 0.81$ & $2.03 \pm 0.66$ & $2.17 \pm 0.75$ & $2.51 \pm 0.82$ & $2.43^{*} \pm 0.61$ & $1.71 \pm 0.82$ & $1.69 * * \pm 0.53$ & $14.77 \pm 2.35$ \\
Basketball & $2.10 \pm 0.61$ & $2.03 \pm 0.18$ & $2.07 \pm 0.45$ & $2.47 \pm 0.51$ & $2.10 \pm 0.40$ & $1.93 \pm 0.64$ & $1.97 \pm 0.18$ & $14.67 \pm 1.27$ \\
\hline
\end{tabular}

Differences between groups: ${ }^{*}-\mathrm{p}<0.05 ; * *-\mathrm{p}<0.01$.

Table 5. Results of bilateral tasks

\begin{tabular}{|c|c|c|c|c|c|c|c|c|c|c|c|c|}
\hline \multirow[t]{2}{*}{ Groups } & \multicolumn{2}{|c|}{ Hurdle step } & \multicolumn{2}{|c|}{ In-line lunge } & \multicolumn{2}{|c|}{ Shoulder mobility } & \multicolumn{2}{|c|}{$\begin{array}{c}\text { Active straight } \\
\text { leg raise }\end{array}$} & \multicolumn{2}{|c|}{ Rotary stability } & \multicolumn{2}{|c|}{ Sum } \\
\hline & right & left & right & left & right & left & right & left & right & left & right & left \\
\hline $\begin{array}{l}\text { Combat } \\
\text { sports }\end{array}$ & $\begin{array}{c}2.27 \\
\pm 0.71\end{array}$ & $\begin{array}{c}2.32 \\
\pm 0.65\end{array}$ & $\begin{array}{c}2.19 \\
\pm 0.67\end{array}$ & $\begin{array}{c}2.24 \\
\pm 0.57\end{array}$ & $\begin{array}{c}2.57 \\
\pm 0.59\end{array}$ & $\begin{array}{c}2.54 \\
\pm 0.60\end{array}$ & $\begin{array}{c}2.57 \\
\pm 0.61\end{array}$ & $\begin{array}{c}2.57 \\
\pm 0.60\end{array}$ & $\begin{array}{l}2.03^{*} \\
\pm 0.60\end{array}$ & $\begin{array}{c}2.19 \\
\pm 0.66\end{array}$ & $\begin{array}{l}11.78 \\
\pm 1.85\end{array}$ & $\begin{array}{l}11.70 \\
\pm 1.65\end{array}$ \\
\hline $\begin{array}{l}\text { Team } \\
\text { sports }\end{array}$ & $\begin{array}{c}2.05 \\
\pm 0.72\end{array}$ & $\begin{array}{c}2.06 \\
\pm 0.51 \\
\end{array}$ & $\begin{array}{c}2.18 \\
\pm 0.53\end{array}$ & $\begin{array}{c}2.23 \\
\pm 0.61\end{array}$ & $\begin{array}{c}2.71 * * \\
\pm 0.68\end{array}$ & $\begin{array}{c}2.54 \\
\pm 0.65\end{array}$ & $\begin{array}{c}2.37 \\
\pm 0.68\end{array}$ & $\begin{array}{c}2.34 \\
\pm 0.52\end{array}$ & $\begin{array}{c}1.85 \\
\pm 0.44\end{array}$ & $\begin{array}{c}1.82 \\
\pm 0.44\end{array}$ & $\begin{array}{l}11.15 \\
\pm 1.53\end{array}$ & $\begin{array}{l}10.98 \\
\pm 1.61\end{array}$ \\
\hline
\end{tabular}

Differences between right and left side: $*-p<0.05 ; * *-p<0.01$. 
Table 6. Results of bilateral tasks in each disciplines

\begin{tabular}{|c|c|c|c|c|c|c|c|c|c|c|c|c|}
\hline \multirow[t]{2}{*}{ Disciplines } & \multicolumn{2}{|c|}{ Hurdle step } & \multicolumn{2}{|c|}{ In-line lunge } & \multicolumn{2}{|c|}{ Shoulder mobility } & \multicolumn{2}{|c|}{$\begin{array}{l}\text { Active straight } \\
\text { leg raise }\end{array}$} & \multicolumn{2}{|c|}{ Rotary stability } & \multicolumn{2}{|c|}{ Sum } \\
\hline & right & left & right & left & right & left & right & left & right & left & right & left \\
\hline Taekwon-do & $\begin{array}{c}2.27 \\
\pm 0.70\end{array}$ & $\begin{array}{c}2.36 \\
\pm 0.72\end{array}$ & $\begin{array}{c}2.23 \\
\pm 0.68\end{array}$ & $\begin{array}{c}2.32 \\
\pm 0.72\end{array}$ & $\begin{array}{c}2.82 \\
\pm 0.39\end{array}$ & $\begin{array}{c}2.77 \\
\pm 0.43\end{array}$ & $\begin{array}{c}2.86 \\
\pm 0.35\end{array}$ & $\begin{array}{c}2.86 \\
\pm 0.35\end{array}$ & $\begin{array}{l}1.91 * \\
\pm 0.61\end{array}$ & $\begin{array}{c}2.18 \\
\pm 0.73\end{array}$ & $\begin{array}{l}12.36 \\
\pm 2.06\end{array}$ & $\begin{array}{l}12.23 \\
\pm 1.77\end{array}$ \\
\hline BJJ & $\begin{array}{c}2.27 \\
\pm 0.59\end{array}$ & $\begin{array}{c}2.27 \\
\pm 0.59\end{array}$ & $\begin{array}{c}2.13 \\
\pm 0.35\end{array}$ & $\begin{array}{c}2.13 \\
\pm 0.35\end{array}$ & $\begin{array}{c}2.20 \\
\pm 0.68\end{array}$ & $\begin{array}{c}2.20 \\
\pm 0.68\end{array}$ & $\begin{array}{c}2.13 \\
\pm 0.64\end{array}$ & $\begin{array}{c}2.13 \\
\pm 0.64\end{array}$ & $\begin{array}{c}2.20 \\
\pm 0.56\end{array}$ & $\begin{array}{c}2.20 \\
\pm 0.56\end{array}$ & $\begin{array}{l}10.93 \\
\pm 1.10\end{array}$ & $\begin{array}{l}10.93 \\
\pm 1.10\end{array}$ \\
\hline Football & $\begin{array}{c}2.03 \\
\pm 0.66\end{array}$ & $\begin{array}{c}2.03 \\
\pm 0.66\end{array}$ & $\begin{array}{c}2.17 \\
\pm 0.75\end{array}$ & $\begin{array}{c}2.17 \\
\pm 0.71\end{array}$ & $\begin{array}{l}2.69 * \\
\pm 0.79\end{array}$ & $\begin{array}{c}2.51 \\
\pm 0.82\end{array}$ & $\begin{array}{c}2.51 \\
\pm 0.56\end{array}$ & $\begin{array}{c}2.51 \\
\pm 0.61\end{array}$ & $\begin{array}{c}1.71 \\
\pm 0.57\end{array}$ & $\begin{array}{c}1.69 \\
\pm 0.53\end{array}$ & $\begin{array}{l}11.11 \\
\pm 1.98\end{array}$ & $\begin{array}{l}10.91 \\
\pm 1.90\end{array}$ \\
\hline Basketball & $\begin{array}{c}2.07 \\
\pm 0.25\end{array}$ & $\begin{array}{c}2.10 \\
\pm 0.31\end{array}$ & $\begin{array}{c}2.20 \\
\pm 0.41\end{array}$ & $\begin{array}{c}2.30 \\
\pm 0.71\end{array}$ & $\begin{array}{c}2.73 \\
\pm 0.45\end{array}$ & $\begin{array}{c}2.57 \\
\pm 0.51\end{array}$ & $\begin{array}{c}2.20 \\
\pm 0.41\end{array}$ & $\begin{array}{c}2.13 \\
\pm 0.43\end{array}$ & $\begin{array}{c}2.00 \\
\pm 0\end{array}$ & $\begin{array}{c}1.97 \\
\pm 0.18\end{array}$ & $\begin{array}{l}11.20 \\
\pm 0.87\end{array}$ & $\begin{array}{l}11.07 \\
\pm 1.20\end{array}$ \\
\hline
\end{tabular}

Differences between right and left side: ${ }^{*}-\mathrm{p}<0.05$.

do athletes in Test 7 (Rotary stability) and for football players in Test 4 (Table 6).

A negative, statistically significant correlation was observed between the number of bodily injuries and the general Functional Movement Screen score. The above relationship was true both for martial arts athletes and team sports players (Fig. 1 and 2).

Among female taekwon-do athletes, a significant negative correlation was noted between the number of bodily injuries and the result of Test 4 (Shoulder mobility). For BJJ players, similar relationships were observed in Test 1 (Deep squat), Test 2 (Hurdle step) and the tallied test result. For football players, valid correlations were observed in Test 3 (In-line lunge) and the tallied test result, and for basketball players in Test 3 (In-line lunge), Test 5 (ASLR) and in the tallied test result (Table 7).

There were no statistically significant correlations between FMS results and training experience, body mass, body height or age of examined people.

\section{Discussion}

The FMS is a simple screening test that highlights functional deficits, as well as asymmetries in studied subjects. It is currently employed not only in amateur and professional-level sports, but also in numerous professional groups (such as soldiers or fire-fighters $[2,7,13$, $24,34,39])$. A great advantage of this test is its reproducibility. It constitutes a basis for planning corrective exercises, aimed strictly at the function. Thanks to this test, the injury risk is diminished by eliminating the risk factors $[4,12,19,33]$.

The FMS test is a tool widely used to assess risk of personal injuries for athletes. Brown [11] assessed the potential of the test in predicting and preventing traumatic bodily injuries for female athletes in various disciplines (volleyball, basketball, football). The female athletes studied by him who scored lower than 16.5 were 4.5 times more prone

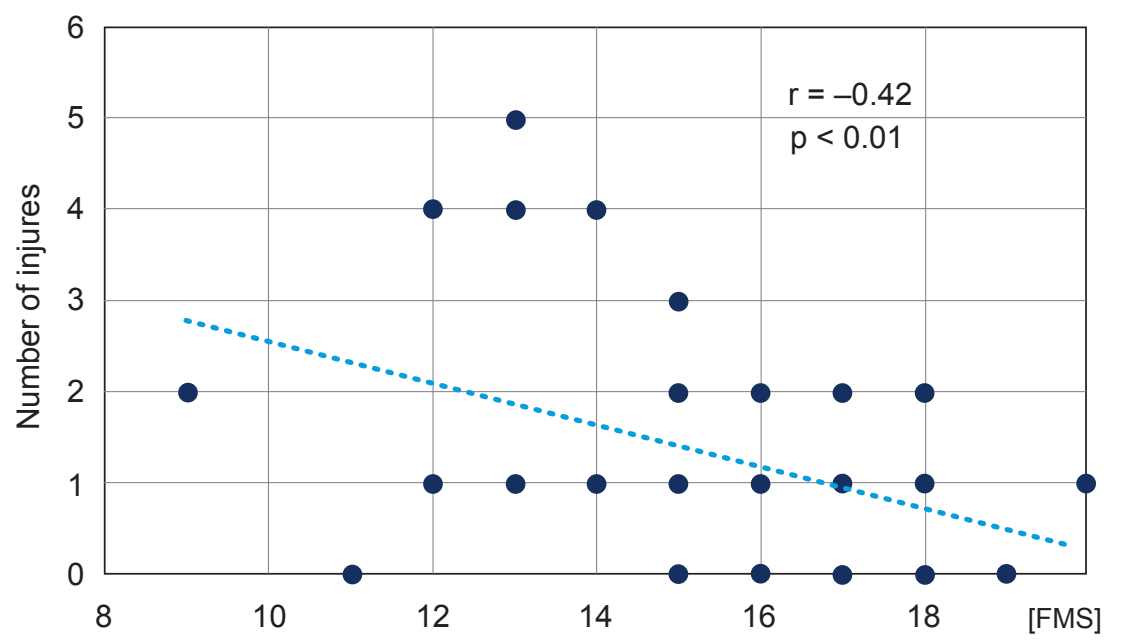

Fig. 1. Correlation between results of FMS and number of injuries in combat sports athletes 


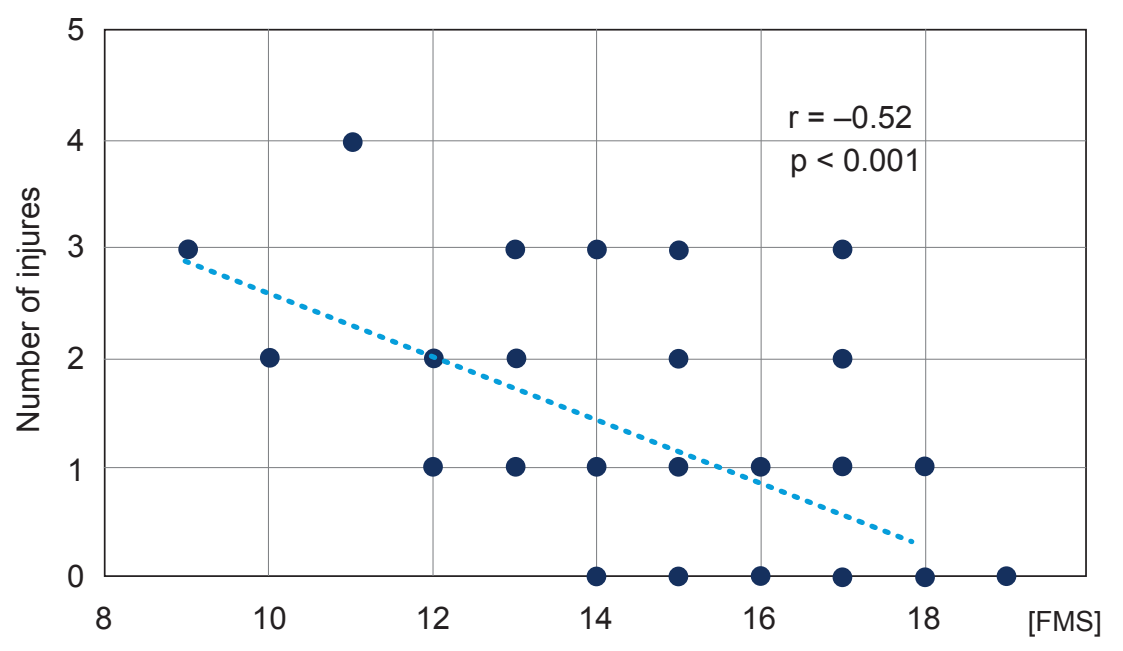

Fig. 2. Correlation between results of FMS and number of injuries in team sports athletes

Table 7. Correlation between results of each tasks of FMS and number of injuries in examined athletes

\begin{tabular}{lcccccccc}
\hline Disciplines & $\begin{array}{c}\text { Deep } \\
\text { squat }\end{array}$ & $\begin{array}{c}\text { Hurdle } \\
\text { step }\end{array}$ & $\begin{array}{c}\text { In-line } \\
\text { lunge }\end{array}$ & $\begin{array}{c}\text { Shoulder } \\
\text { mobility }\end{array}$ & $\begin{array}{c}\text { Active straight } \\
\text { leg raise }\end{array}$ & $\begin{array}{c}\text { Trunk stability } \\
\text { push-up }\end{array}$ & $\begin{array}{c}\text { Rotary } \\
\text { stability }\end{array}$ & Sum \\
\hline Taekwon-do & -0.360 & -0.123 & -0.056 & $-0.664 * * *$ & -0.150 & 0.273 & -0.090 & -0.226 \\
BJJ & $-0.698^{* *}$ & $-0.588^{*}$ & -0.433 & 0.312 & -0.444 & -0.284 & -0.094 & $-0.728^{* * *}$ \\
Football & -0.270 & -0.122 & $-0.483^{* *}$ & -0.236 & -0.167 & -0.215 & -0.134 & $-0.512^{* *}$ \\
Basketball & -0.216 & -0.240 & $-0.431^{*}$ & -0.298 & $-0.414 *$ & -0.085 & 0.045 & $-0.578^{* * *}$ \\
\hline
\end{tabular}

$*-\mathrm{p}<0.05 ; * *-\mathrm{p}<0.01 ; * * *-\mathrm{p}<0.001$.

to injuries in a given season. A statistically significant difference $(p<0.05)$ was noted for volleyball $(17.36 \pm 1.22$, $\mathrm{n}=14)$ and basketball players $(15.76 \pm 1.86, \mathrm{n}=17)[12]$. Our studies did not concern traumatic bodily injury prevention, yet they have demonstrated a relationship between past bodily injuries and the FMS test results.

Similar findings were noted by Chorba et al. [16]. Studies on female football, volleyball and basketball players have demonstrated that for athletes scoring lower than 14 in the FMS, the risk of contracting an injury was 4-fold higher. According to the authors, the compensations in the musculoskeletal system increase the risk of injury. Conducting the FMS test makes it possible to predict potential injuries without a detailed history of prior bodily injuries [16].

The above correlation was not observed by Mokha et al. [30], who, while studying volleyball and football players of both sexes, defined asymmetries as the main cause of injuries. According to them, it is precisely the asymmetries and lower scores in individual FMS tests that influence the risk of contracting a bodily injury, rather than the tallied score of the test [30].

Studies on American football players have demonstrated that those who scored significantly different results in the FMS test were prone to a higher risk of bodily injuries for both sides of the body. The study involved 62 healthy athletes who had individual training introduced during the seasonal break. The corrective training was based on the test result and was aimed at obtaining better results in asymmetrical exercises. Before introducing this training, 31 athletes were free from asymmetry, and after the training round, 41 were free from asymmetry. Test 1 (Deep squat) has proven to be the most appropriate assessment indicator [27]. Valid asymmetries (in particular tests) were noted among the studied taekwon-do and football athletes. It may make an individual more prone to bodily injuries. Therefore, it would be useful to introduce an intervention to eradicate the above disparities.

The results obtained in FMS may be impacted by training experience and the sports class. Adamczyk et al. [3] confirmed the relationship between the average FMS score and the training experience for weightlifters. The authors found a correlation between the sports level and the functional assessment. The higher the levels of sports was, the higher was the functional level of the athletes. A positive effect of exercises employed in specialised weightlifters training on the functionality of the athletes was observed, which justifies the need to introduce them in the general fitness training as a means to prevent bodily injuries [3].

Abraham et al. [1] described FMS as an ancillary tool to screen potential candidates to practise a certain discipline, 
to identify athletes prone to injuries. They studied a group of boys and girls aged 10 to 17 . A statistically significant difference was observed between the results obtained by the studied boys and girls (the average result was 14.59, and scores obtained by girls were lower). On the other hand, no correlations were observed between the test results and previously contracted injuries [1].

One of the disadvantages of our research may be the subjective nature of the Functional Movement Screen assessment. Nevertheless, this impression is minimised by the necessity to perform the assessment in the sagittal and coronal planes. Moreover, the criteria for each grade are clearly identified and globally standardised. Another drawback might be the small representation of girls. However, it is the consequence of a generally smaller number of women than men among combat sports athletes.

It is therefore necessary to continue FMS testing in athletes in different disciplines. It will enable the coaches to better prepare the training schemes to avoid injuries, which often bring the careers to a close. Low cost and the ability to assess the multiple dimensions of the movement, and not just particular fitness indicators, may be considered advantages of the test.

\section{Conclusions}

1. Female combat and team sports athletes encounter functional limitations which may prove their proneness to bodily injuries. It therefore seems advisable to introduce an intervention programme aimed at reducing the observed malfunctions and diminishing the risk of bodily injuries.

2. A negative correlation was observed between the test results and the number of injuries contracted by the studied athletes. Physiotherapist functional assessment tests may constitute a tool useful in bodily injury prevention, making it possible to employ a suitable intervention to diminish muscular imbalance, movement constraints or asymmetry.

3. The results obtained here may constitute a basis for further research on larger groups of women practising various sport disciplines.

Conflict of interest: Authors state no conflict of interest.

\section{References}

1. Abraham A., Sannasi R., Nair R. (2015) Normative values for the functional movement screen in adolescent school aged children. Int. J. Sports Phys. Ther, 10(1): 29-36.
2. Adamczyk J.G., Boguszewski D., Białoszewski D. (2015) Functional assessment of male track and field runners through Functional Movement Screen test. Med. Sport, 68(4): 563-575.

3. Adamczyk J.G., Pepłowski M., Boguszewski D., Białoszewski D. (2012) Functional evaluation of competitors practising weightlifting with using Functional Movement Screen Test. Polish J. Sport. Med., 28(4): 267-276.

4. Bardenett S.M., Micca J.J., DeNoyelles J.T., Miller S.D., Jenk D.T., Brooks G.S. (2015) Functional Movement Screen normative values and validity in high school athletes: can the FMS be used as a predictor of injury? Int. J. Sports Phys. Ther., Jun, 10(3): 303-308.

5. Beijsterveldt A., Port I., Krist M., Schmikli S.L., Stubbe J.H., Frederiks J.E., Backx F.J. (2012) Effectiveness of an injury prevention programme for adult male amateur soccer players: a cluster-randomised controlled trial. Br. J. Sports Med., 46: 1114-1118.

6. Bliven K.C.H., Anderson B.E. (2013) Core stability training for injury prevention. Sports Health, 5(6): 514-522.

7. Boguszewski D. (2015) Application of physiotherapeutic methods to support training and post-exercise recovery of combat sports and martial arts contestants. J. Combat Sports Martial Arts, 6(2): 85-90.

8. Boguszewski D., Adamczyk J.G., Buda M., Kłoda M., Białoszewski D. (2016) The use of functional tests to assess risk of injuries in judokas Arch. Budo Sci. Martial Art Extreme Sport, 12: 57-62.

9. Boguszewski D., Falkowska M., Adamczyk J.G., Białoszewski D. (2017) Influence of foam rolling on the functional limitations of the musculoskeletal system in healthy women. Biomed. Hum. Kinet., 9(1): 75-81.

10. Boguszewski D., Jakubowska K., Adamczyk J.G., Ochal A., Białoszewski D. (2017) Functional assessment of children practicing ice hockey through Functional Movement Screen test. Physical Activity Review, 5: 105-112.

11. Bompa T.O., Haff G.G. (2009) Periodization. Theory and Methodology of Training. Human Kinetics, Champaign.

12. Brown M. (2011) The ability of the functional movement screen in predicting injury rates in Division 1 female athletes. Theses and Dissertations, Paper 541, Toledo. http://utdr.utoledo.edu/cgi/viewcontent. cgi? article $=1562 \&$ context $=$ theses-dissertations

13. Butler R.J., Contreras M., Burton L.C., Plisky P.J., Goode A., Kiesel K. (2013) Modifiable risk factors predict injuries in firefighters during training academies. Work, 46(1): 11-17.

14. Calleja-González J., Terrados N., Mielgo-Ayuso J., Delextrat A., Jukic I., Vaquera A., Torres J., Schelling X., Stojanovic M., Ostojic S.M. (2016) Evidence-based postexercise recovery strategies in basketball. Phys. SportsMed., 44(1): 74-78. 
15. Chimera N.J., Smith C.A., Warren M. (2015) Injury history, sex, and performance on the functional movement screen and Y balance test. J. Athl. Train., 50(5): 475-485.

16. Chorba R.S., Chorba D.J., Bouillon L.E., Overmyer C.A., Landis J.A. (2010) Use of a functional movement screening tool to determine injury risk in female collegiate athletes. N. Am. J. Sports Phys. Ther., 5: 47-54.

17. Cook G., Burton L., Hoogenboom B.J., Voight M. (2014) Functional Movement Screening: the use of fundamental movements as an assessments of function - part 1. Int. J. Sports Phys. Ther., 3: 396-409.

18. Cook G., Burton L., Hoogenboom B.J., Voight M. (2014) Functional Movement Screening: the use of fundamental movements as an assessments of function - part 2. Int. J. Sports Phys. Ther., 4: 549-563.

19. Hammes D., Aus der Fünten K., Bizzini M., Meyer T. (2016) Injury prediction in veteran football players using the Functional Movement Screen. J. Sports Sci., Jul, 34(14): 1371-1379.

20. Herman K., Barton C., Malliaras P., Morrissey D. (2012) The effectiveness of neuromuscular warm-up strategies, that require no additional equipment, for preventing lower limb injuries during sports participation: a systematic review. BMC Medicine, 10: 75. DOI: 10.1186/1741-7015 $-10-75$.

21. Hupperets M.D., Verhagen E.A., Van Mechelen W. (2009) Effect of unsupervised home based proprioceptive training on recurrences of ankle sprain: randomised controlled trial. $B M J, 339: \mathrm{b} 2684$.

22. Kalina R.M., Barczyński B., Klukowski K., Langfort J., Gąsienica-Walczak B. (2011) The method to evaluate the susceptibility of injuries during the fall - validation procedure of the specific motor test. Arch. Budo, 7(4): 201-215.

23. Kalina R.M., Jagiełło W., Barczyński B.J. (2013) The method to evaluate the body balance disturbation tolerance skills - validation procedure of the Rotational Test. Arch. Budo, 9: 59-80.

24. Karakurt S., Aggon E. (2018) Effect of dynamic and static strength training using Thera-Band $\AA$ on elite athletes muscular strength. Arch. Budo, 14: 339-343.

25. Kiani A., Hellquist E., Alhqvist K., Gedeborg R., Michaelson K., Byberg L. (2010) Prevention of Soccer-Related Knee Injuries in Teenaged Girls. Arch. Intern. Med., 170: 43-49.

26. Kiesel K., Plisky P., Butler R. (2011) Functional movement test scores improve following a standardized offseason intervention program in professional football players. Scand. J. Med. Sci. Sports, 21(2): 287-292.

27. Kiesel K.B., Butler R.J., Plisky P.J. (2014) Prediction of injury by limited and asymmetrical fundamental movement patterns in American football players. J. Sport Reh., 23(2): 88-94.
28. Laskowski R. (2010) Symptoms of sexual dimorphism in judoists. J. Combat Sports Martial Arts, 1(1): 45-52.

29. McGuine T.A., Brooks A., Hetzel S. (2011) The effect of lace-up ankle braces on injury rates in high school basketball players. Am. J. Sports Med., 39: 1840-1848.

30. Mokha M., Sprague P.A., Gatens D.R. (2016) Predicting Musculoskeletal Injury in National Collegiate Athletic Association Division II Athletes From Asymmetries and Individual-Test Versus Composite Functional Movement Screen Scores. J. Athl. Train., 51(4): 276-282.

31. Mosler D. (2015) Usability of non-apparatus and quasi apparatus flexibility tests based on self-perception participants in health-related judo training. Arch. Budo Sci. Martial Art Extreme Sport, 11: 189-197.

32. Myer G.D., Chu D.A., Brent J.L., Hewett T.E. (2008) Trunk and hip control neuromuscular training for the prevention of knee joint injury. Clin. Sports Med., 27(3): 425-448.

33. Nikolaidis P.T. (2010) Core stability of male and female football players. Biomed. Hum. Kinet., 2: 30-33. DOI: 10.2478/v10101-010-0007-9.

34. Poomsalood S., Muthumayandi K., Hambly K. (2019) Can stretch sensors measure knee range of motion in healthy adults? Biomed. Hum. Kinet., 11(1): 1-8.

35. Schroeder J., Wellmann K., Stein D., Braumann K.M. (2016) The Functional Movement Screen for Injury Prediction in Male Amateur Football. Dtsch. Z. Sportmed., 67: 39-43.

36. Sterkowicz-Przybycień K., Ambroży T. (2013) Sexual dimorphism in anthropometric and fitness measurements of top ju-jitsu contestants. J. Combat Sports Martial Arts, 4(2): 145-152.

37. Sterkowicz-Przybycień K., Fukuda D.H. (2016) Sex differences and the effects of modified combat regulations on endurance capacity in judo athletes: A meta-analytic approach. J. Hum. Kinet., 51: 113-120.

38. Syczewska M., Krawczyk M., Szczerbik E., Kalinowska M. (2017) Timing of electromyographic activity and ranges of motion during simple motor tasks of upper extremities. Biomed. Hum. Kinet., 9(1): 146-157.

39. Teyhen D.S., Shaffer S.W., Butler R.J., Goffar S.L., Kiesiel K.B., Rhon D.I., Wiliamson J.N., Plisky P.J. (2015) What risk factors are associated with muscoskeletal injury in US Army Rangers? A prospective prognostic study. Clin. Orthop. Relat. Res., 473(9): 2948-2958.

40. Yarar H., Karli U., Aydin K., Erdem H., Uzum H. (2013) Effect of Using Mouth Guard on Anaerobic and Aerobic Performance of Combat Sport Athletes. Int. J. Sport Stud., 3(7): 719-725.

\section{Received 20.03.2019 \\ Accepted 03.06.2019}

(c) University of Physical Education, Warsaw, Poland 